Ambiente \& Água - An Interdisciplinary Journal of Applied Science
ISSN 1980-993X - doi:10.4136/1980-993X
www.ambi-agua.net
E-mail: ambi.agua@gmail.com

\title{
Potencial de efluente de esgoto doméstico tratado como fonte de água e nutrientes no cultivo hidropônico de alface
}

\author{
doi: 10.4136/ambi-agua.1575 \\ Received: 09 Dec. 2014; Accepted: 17 Apr. 2015

\begin{abstract}
Renata da Silva Cuba; João Rios do Carmo; Claudinei Fonseca Souza*; Reinaldo Gaspar Bastos
\end{abstract} \\ Universidade Federal de São Carlos (UFSCAR) Araras, SP, Brasil \\ Centro de Ciências Agrárias (CCA) \\ *Autor correspondente: e-mail: cfsouza@cca.ufscar.br, \\ renatacuba@hotmail.com,jriosagro@hotmail.com,reinaldo@cca.ufscar.br
}

\section{RESUMO}

A busca por fontes alternativas de água para a agricultura torna o uso de efluentes de esgotos tratados na agricultura uma estratégia importante para atingir a sustentabilidade. Este trabalho avaliou a viabilidade do reuso de efluente de esgoto doméstico tratado, como fonte alternativa de água e nutrientes no cultivo hidropônico de alface (Lactuca sativa L). O experimento foi realizado no Centro de Ciências Agrárias - UFSCar, no município de Araras (SP), em casa de vegetação. O cultivo ocorreu de fevereiro a março de 2014. O sistema hidropônico adotado foi a técnica do filme de nutrientes e contou com três tratamentos: 1) uso de água de abastecimento e fertilizantes minerais (TA), 2) uso de efluente doméstico tratado, complementado com fertilizantes minerais, com base em resultados de análise química prévia (TRA) e, 3) uso de efluente doméstico tratado (TR). O delineamento experimental aplicado foi o de quatro blocos distribuídos ao acaso. Avaliou-se a massa fresca, o estado nutricional, a qualidade microbiológica da cultura e a quantidade de fertilizantes aplicados nos tratamentos. Os dados de massa fresca foram submetidos à análise de variância e as médias foram comparadas pelo teste de Tukey a 5\% de probabilidade. Apenas o tratamento TR apresentou diferença significativa quanto às variáveis avaliadas, sendo identificados sintomas de deficiências nutricionais nas plantas e redução significativa na produção de massa fresca ( $\mathrm{p}<0,01$ ). Não foi detectada presença de Escherichia coli em nenhum dos tratamentos, sendo possível obter uma economia de alguns fertilizantes no tratamento TRA em comparação ao TA.

Palavras chave: efluente, Lactuca sativa L, hidroponia, solução nutritiva, sustentabilidade.

\section{Potential of domestic sewage effluent treated as a source of water and nutrients in hydroponic lettuce}

\begin{abstract}
The search for alternative sources of water for agriculture makes the use of treated sewage sludge an important strategy for achieving sustainability. This study evaluated the feasibility of reusing treated sewage effluent as alternative source of water and nutrients for the hydroponic cultivation of lettuce (Lactuca sativa $\mathrm{L}$ ). The experiment was conducted in the
\end{abstract}


greenhouse of the Center for Agricultural Sciences - UFSCar, in Araras, SP. The cultivation took place from February to March 2014. The hydroponic system used was the Nutrient Film Technique, and included three treatments: 1) water supply and mineral fertilizers (TA); 2) use of effluent treated and complemented with mineral fertilizers based on results of previous chemical analysis (TRA); and 3) use of treated effluent (TR). The applied experimental design was four randomly distributed blocks. We evaluated the fresh weight, nutritional status, the microbiological quality of the culture, and the amount of mineral fertilizers used in the treatments. The fresh weights were subjected to analysis of variance and means were compared by the Tukey test at 5\% probability. Only the TR treatment showed a significant difference in the evaluated variables, as symptoms of nutritional deficiencies in plants and significant reduction in fresh weights $(\mathrm{p}<0.01)$ were found. There was no detectable presence of Escherichia coli in any treatment, and it was possible to use less of some fertilizers in the TRA treatment compared to TA.

Keywords: Lactuca sativa L, effluent, hydroponic, nutrient solution, sustainability.

\section{INTRODUÇÃO}

A expansão urbana, o crescimento da população e, consequentemente, o desenvolvimento da indústria e da agricultura, levaram à degradação dos recursos naturais, dentre eles, a água. Durante muitos anos, este recurso foi considerado inesgotável e, somente nas últimas décadas, tomou-se consciência da situação de escassez e da necessidade de racionalizar seu uso, procurar formas de reuso e recuperação da sua qualidade. A agricultura é responsável por cerca de $70 \%$ do consumo global de água (WHO, 2013), e em muitas situações não permite o seu reuso direto por se tratar de um uso consuntivo, onde a água utilizada na irrigação é evapotranspirada pelas plantas e depois incorporada ao vapor d'água da atmosfera, não sendo diretamente reaproveitada.

O interesse em usar água residuária tratada na irrigação e indústria é objetivo de estudos mais recentes (Keller et al., 2005; Sousa et al., 2006; Azevedo et al., 2007; Al-Boon e AlAnanzeh, 2008; Bonini et al., 2014), e se tornou uma opção atraente, pois reduz a contaminação pela descarga direta de esgoto nos corpos hídricos, melhorando as condições de potabilidade, permitindo a utilização mais racional dos recursos hídricos, sendo uma fonte alternativa de água disponível (Martínez et al., 2013). Assim, o uso de esgotos tratados na agricultura pode se tornar importante ferramenta na gestão da água. A decisão crítica da elaboração de políticas sobre a aplicação do esgoto tratado pode contribuir para transformar a imagem negativa do esgoto em uma prática economicamente e ambientalmente segura, no sentido de preservar os recursos hídricos (Hespanhol, 2002).

A utilização do esgoto tratado pode representar uma fonte de água e nutrientes disponível para aplicação na agricultura, mesmo durante os períodos de estiagem (Shaer-Barbosa et al. 2014). Por outro lado, a segurança da reutilização dessas águas residuárias para fins de irrigação é motivo de cautela. Em geral, as normas vigentes para a reutilização de esgoto tratado especificam os padrões de qualidade microbiológica, considerando os tratamentos mínimos requeridos para os efluentes, o tipo de cultura a ser irrigada e aos métodos de irrigação empregados (Perin, 2006). No Brasil, a Resolução 54/2005 (CNRH, 2006), estabelece somente os critérios gerais para o reuso de água potável e reuso direto não potável, modalidades e diretrizes, porém não são estabelecidos os parâmetros e recomendações necessários à está prática. Segundo a FAO (1992), sempre que águas residuárias forem consideradas como fonte de água na agricultura, a escolha do sistema apropriado de aplicação e uso poderá ser decisivo na produtividade da cultura, na diminuição da contaminação da cultura e do ambiente, na segurança humana, na salinidade e nos riscos de toxicidade. 
A hidroponia, que pode ser definida como o cultivo de plantas sem solo, é uma técnica que apresenta potencial para aplicação de águas residuárias, pois somente o sistema radicular da planta tem contato direto com a água. O uso da hidroponia, segundo Melo et al. (2002), surgiu como uma alternativa a problemas como a baixa disponibilidade de solos aptos à agricultura; a incidência de determinadas doenças de solo, dificilmente controladas por métodos químicos, sanitários ou de resistência genética; o interesse em incrementar a eficiência do uso da água e o desejo de aumentar a produção e melhorar a qualidade dos alimentos.

Dentre as culturas hidropônicas, a alface é a espécie mais cultivada, e segundo Sala e Costa (2012) é um setor em franca expansão devido aos avanços tecnológicos, e também pela redução dos riscos, previsibilidade e constância da produção neste tipo de sistema. Ainda de acordo com Boyden e Rababah (1996), uma cultura de alface hidropônica é capaz de extrair aproximadamente $77 \%$ do fósforo e $80 \%$ do nitrogênio contidos na solução de efluentes de tratamento de esgoto sanitário, mostrando que além de presentes na solução, estes nutrientes também estão disponíveis para serem absorvidos.

Além do mais, Rababah e Asbolt (2000) apontam o uso da hidroponia para o tratamento de águas residuárias e para incrementar a produção de alimentos como um exemplo de economia na gestão da água, afirmando que é possível diminuir o consumo de energia através da redução do bombeamento de águas residuais entre cidades, por meio da aplicação localizada de tecnologias de recuperação, citando a hidroponia como uma destas. Segundo Ottoson et al. (2005) o sistema de cultivo hidropônico é capaz de reduzir a carga microbiana do efluente através da adsorção dos mesmos nas raízes e também pelo tempo de detenção hidráulica prolongado, uma vez que a água circula em um sistema fechado. Os mesmos autores acima citados, afirmam que a hidroponia também contribui para reduzir os teores de nitrogênio e fósforo do efluente. Porém, quando se utiliza efluente como solução nutritiva o balanço nutricional nem sempre é o mais adequado, pois determinadas culturas necessitam de composição estequiométrica de nutrientes (Florencio et al., 2006), havendo obrigatoriamente, alguns ajustes no meio.

No contexto da necessidade de pesquisas e estudos para viabilizar o reuso da água, a hidroponia surge como alternativa de aproveitamento dos efluentes, podendo obter como vantagens, a redução do lançamento em cursos d'água, a ciclagem dos nutrientes que não foram totalmente eliminados no processo de tratamento utilizado, a possibilidade de instalação da infraestrutura necessária próxima à estação de tratamento, reduzindo custos com transporte do efluente, bem como, a mitigação adicional de riscos a saúde, ao minimizar o contato efluente-planta e o agricultor.

Portanto, o objetivo deste trabalho foi avaliar o aproveitamento de um efluente doméstico, proveniente de uma Estação de Tratamento de Esgoto (ETE) do Centro de Ciências Agrárias (CCA) da Universidade Federal de São Carlos (UFSCar), como alternativa para o cultivo hidropônico de alface (Lactuca sativa $\mathrm{L}$ ).

\section{MATERIAL E MÉTODOS}

O cultivo hidropônico de alface foi realizado nas instalações do Departamento de Recursos Naturais e Proteção Ambiental (DRNPA) do CCA - UFSCar (Centro de Ciências Agrárias - Universidade Federal de São Carlos), localizado no município de Araras, Estado de São Paulo, com latitude $22^{\circ} 18^{\prime} 53.23^{\prime \prime}$ S e longitude de $47^{\circ} 23^{\prime} 00.91^{\prime \prime} O$. O clima da região é caracterizado por duas estações bem definidas, sendo uma seca, de abril a setembro, e outra chuvosa, de outubro a março, e enquadra-se no tipo "Cwa" de Köppen (Setzer, 1967), com uma precipitação média anual de $1300 \mathrm{~mm}$. 
O estudo foi desenvolvido em casa de vegetação, composta por estrutura metálica do tipo teto em arco, coberta com polietileno transparente, com altura de $3 \mathrm{~m}$ e dimensão de $20 \mathrm{~m}$ de comprimento por $6,40 \mathrm{~m}$ de largura, com laterais fechadas por tela, do tipo sombrite. $\mathrm{O}$ cultivo ocorreu no período de 05 de fevereiro a 11 de março de 2014, sendo que as plantas de alface ficaram 14 dias no berçário hidropônico para aclimatação e 21 dias no sistema hidropônico definitivo. A cultivar selecionada foi a "Vanda", que é do segmento crespa, uma vez que segundo Sala e Costa (2012), é o tipo que predomina no mercado brasileiro.

\subsection{Descrição do experimento}

A estrutura utilizada foi composta por doze bancadas de cultivo, com três metros de comprimento cada uma e quatro perfis hidropônicos de polipropileno $(75 \mathrm{~mm})$ por bancada (Figura 1). O delineamento experimental utilizado foi em blocos ao acaso, com três tratamentos, e quatro repetições, que totalizaram doze parcelas.

O primeiro tratamento foi alimentado com água de abastecimento e fertilizantes minerais (TA), o segundo por esgoto doméstico tratado, complementado com fertilizantes minerais, com base nos resultados da análise química (TRA) e o terceiro, somente com esgoto doméstico tratado (TR), que também foi analisado quanto à composição química. O sistema hidropônico adotado foi a Técnica do Filme de Nutriente (NFT) (Martinez, 2006), e cada tratamento foi composto por um reservatório com capacidade para armazenar $500 \mathrm{~L}$ de solução nutritiva, um sistema de bombeamento, quatro parcelas (bancadas) contendo quatro perfis hidropônicos e um sistema de retorno da solução nutritiva por gravidade ao reservatório.

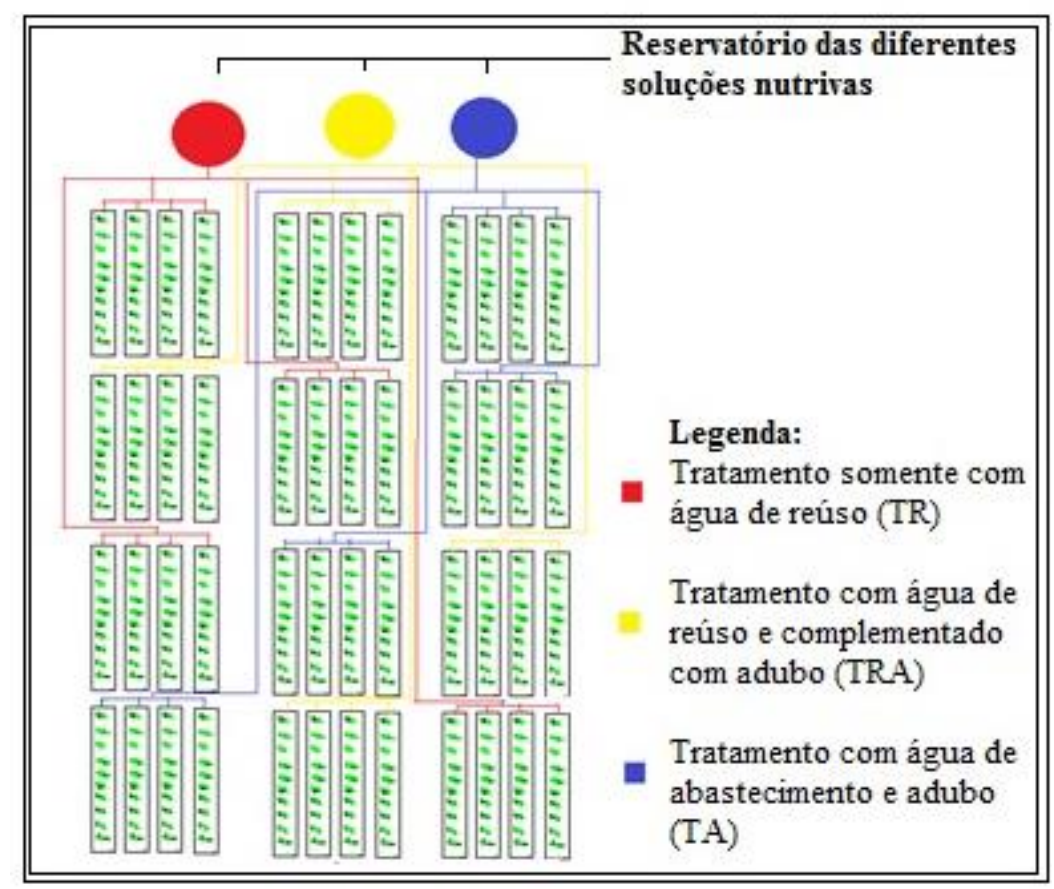

Figura 1. Representação esquemática da estrutura hidropônica e da distribuição dos tratamentos.

O espaçamento entre perfis hidropônicos foi de $0,30 \mathrm{~m}$, entre plantas de $0,25 \mathrm{~m}$ e a distância entre as bancadas de $0,70 \mathrm{~m}$ para permitir o manuseio. Desta forma, trabalhou-se com 12 plantas por perfil, sendo 48 por parcela e 192 plantas por tratamento. A declividade usada foi de $10 \%$ para facilitar o escoamento da solução nutritiva por gravidade e também para melhorar a sua oxigenação e diminuir o seu aquecimento. A vazão média mantida em cada canal foi de 1,5 $\mathrm{L} \mathrm{min}^{-1}$, conforme proposto por Martinez e Silva Filho (2004). O sistema 
funcionou por meio de um temporizador, que acionava o conjunto motobomba, fornecendo a solução em intervalos regulares, programado para permanecer o fluxo intermitente, com ligação a cada 15 minutos no período diurno e de 15 minutos a cada hora no período noturno, conforme Furlani (1999).

\subsection{Esgoto doméstico tratado}

O esgoto doméstico tratado foi captado na saída da ETE, que é composta por quatro unidades: tanque séptico, tanque de microalgas, filtro anaeróbio de fluxo ascendente e wetlands (leitos cultivados). As unidades são estanques, de material impermeabilizado (polietileno), para evitar vazamentos e consequente contaminação do solo, lençol freático ou aquífero subterrâneo. Essa estação foi dimensionada para receber e tratar $2000 \mathrm{~L}$ de esgoto diariamente, proveniente do restaurante universitário e sanitários.

A caracterização do esgoto tratado foi realizada antes de sua aplicação nos tratamentos, e após passar por todas as unidades de tratamento da ETE, para calcular a necessidade de complementação com fertilizante mineral no tratamento TRA. Para isso, foram coletadas amostras semanais do esgoto tratado na saída de ETE, utilizando frascos de 0,5 L esterilizados segundo metodologia da CETESB (2011), e conduzidas ao Laboratório de Poluição do Solo do CCA- UFSCar, para análise dos parâmetros físicos, químicos e microbiológicos: pH, turbidez, demanda bioquímica de oxigênio $\left(\mathrm{DBO}_{5,20}\right)$, oxigênio dissolvido (OD), condutividade elétrica (CE), fósforo total (P), nitrogênio total Kjeldahl (NTK), coliformes totais e Escherichia coli. Os demais parâmetros químicos, como os teores de cálcio $(\mathrm{Ca})$, sódio $(\mathrm{Na})$, potássio $(\mathrm{K})$, magnésio $(\mathrm{Mg})$, foram analisados no Laboratório de Fertilidade do Solo do CCA- UFSCar, conforme metodologia sugerida por Blum (2003). As metodologias adotadas nas avaliações estão de acordo com o Standard Methods for the Examination of Water and Wastewater (APHA, 2012). As análises físico-químicas foram semanais, totalizando quatro análises durante o cultivo, e as microbiológicas somente no final do cultivo.

Para as análises microbiológicas, optou-se pelo uso do Método Enzimático (Sistema Colilert da IDEXX; referências à marca registrada não constituem endosso por parte dos autores), pela facilidade de operação e obtenção dos resultados de Coliformes totais e Termotolerantes (Escherichia coli) em 24 horas, em número mais provável (NPM), sendo aceito pelo Standard Methods for the Examination of Water and Wastewater (APHA, 2012).

\subsection{Solução Nutritiva}

O preparo da solução nutritiva para os tratamentos TA e TRA foi realizado com base na recomendação para a cultura de alface, proposta por Martinez e Silva Filho (2004). No tratamento TRA a complementação com fertilizantes minerais foi realizada considerando o resultado das análises químicas.

Para manter o meio de cultivo favorável ao desenvolvimento das plantas no sistema hidropônico, foi realizado o monitoramento diário do $\mathrm{pH}$ e da condutividade elétrica das soluções. A reposição de água e fertilizantes foram semanais, usando como recomendação a redução de $30 \%$ da condutividade elétrica do valor inicial, conforme proposto por Martinez e Silva Filho (2004).

\subsection{Análises das Plantas de Alface}

As análises dos teores de nutrientes foliares da alface foram realizadas quando a cultura apresentava dois terços do seu desenvolvimento, seguindo a metodologia proposta por Raij et al. (1997).

Aos 21 dias após o transplantio no local definitivo as plantas atingiram o desenvolvimento adequado para a colheita. Inicialmente foi realizada a coleta ao acaso de folhas recém desenvolvidas e folhas próximas as raízes, usando luvas e sacos plásticos 
estéreis, em cada parcela, para análise microbiológica das plantas, e em seguida foram encaminhadas para o Laboratório de Microbiologia Aplicada do CCA- UFSCar. Foi adotada a metodologia das placas Petrifilm da 3M (referências à marca registrada não constituem endosso por parte dos autores) para coliformes totais e termotolerantes (Escherichia coli).

Após a coleta para a análise microbiológica fez-se a colheita de 03 plantas ao acaso de cada parcela e realizou-se a pesagem das amostras em balança analítica para determinar a massa fresca média por planta de cada tratamento.

As amostras para a análise microbiológica foram manipuladas em câmara de fluxo laminar em solução de peptona $0,1 \%$, sendo posteriormente incubadas por 24 horas a $35^{\circ} \mathrm{C}$ em estufa de germinação e novamente em câmara do fluxo laminar inoculadas nas placas Petrifilm. Após o período de incubação de 24 e 48 horas, procedeu-se a contagem de Coliformes totais e Termotolerantes (Escherichia coli), respectivamente.

As análises estatísticas foram realizadas com o auxílio do programa estatístico Instat versão 3.6. Calculou-se a média por planta da massa fresca total (raízes e parte aérea) das amostras colhidas de cada tratamento, e os resultados médios foram submetidos ao teste estatístico de Tukey para verificar se houve diferença significativa $(p \geq 0,05)$ entre os tratamentos.

\section{RESULTADOS E DISCUSSÃO}

\subsection{Análise do efluente}

De acordo com os resultados apresentados na Tabela 1, verificou-se que o efluente estudado apresentou baixos teores de nutrientes para ser usado como solução nutritiva, considerando a recomendação de Martinez e Silva Filho (2004) para o cultivo hidropônico da alface.

Tabela 1. Caracterização físico-química e microbiológica das amostras semanais de esgoto doméstico tratado proveniente da ETE do CCA da UFSCar, em Araras (SP).

\begin{tabular}{|c|c|c|c|c|c|c|}
\hline \multirow[b]{2}{*}{ Parâmetros } & \multicolumn{6}{|c|}{ Resultados das análises } \\
\hline & $\begin{array}{c}1^{\mathrm{o}} \\
\text { amostra }\end{array}$ & $\begin{array}{c}2^{\circ} \\
\text { amostra }\end{array}$ & $\begin{array}{c}3^{\circ} \\
\text { amostra }\end{array}$ & $\begin{array}{c}4^{\circ} \\
\text { amostra }\end{array}$ & Média & $\begin{array}{l}\text { Desvio } \\
\text { padrão }\end{array}$ \\
\hline $\mathrm{pH}$ & 7,83 & 8,00 & 8,31 & 8,24 & 8,10 & 0,22 \\
\hline $\left.\mathrm{CE}^{1}(\mathrm{dS} \mathrm{m})^{-1}\right)$ & 0,50 & 0,40 & 0,50 & 0,50 & 0,48 & 0,05 \\
\hline $\mathrm{DBO}_{5,20}^{2}\left(\mathrm{mg} \mathrm{L}^{-1}\right)$ & 18,00 & 16,50 & 21,70 & 18,00 & 18,55 & 2,21 \\
\hline $\mathrm{OD}^{3}\left(\mathrm{mg} \mathrm{L}^{-1}\right)$ & 4,10 & 4,40 & 3,80 & 4,20 & 4,12 & 0,25 \\
\hline $\mathrm{NTK}^{4}\left(\mathrm{mg} \mathrm{L}^{-1}\right)$ & 1,40 & 50,00 & 75,00 & 49,00 & 43,85 & 30,75 \\
\hline $\mathrm{P}^{5}\left(\mathrm{mg} \mathrm{L}^{-1}\right)$ & 2,70 & 7,40 & 2,45 & 9,85 & 5,60 & 3,63 \\
\hline $\mathrm{K}\left(\mathrm{mg} \mathrm{L}^{-1}\right)$ & 33,58 & 10,00 & 4,00 & 5,00 & 13,15 & 13,87 \\
\hline $\mathrm{Ca}\left(\mathrm{mg} \mathrm{L}^{-1}\right)$ & 18,50 & 6,35 & 3,73 & 2,29 & 7,72 & 7,38 \\
\hline $\operatorname{Mg}\left(\mathrm{mg} \mathrm{L}^{-1}\right)$ & 5,68 & 3,03 & 1,01 & 2,90 & 3,16 & 1,92 \\
\hline $\mathrm{S}\left(\mathrm{mg} \mathrm{L}^{-1}\right)$ & 35,30 & 29,70 & 28,15 & 39,40 & 33,14 & 5,18 \\
\hline $\mathrm{Na}\left(\mathrm{mg} \mathrm{L}^{-1}\right)$ & 49,00 & 53,00 & 55,00 & 51,00 & 52,00 & 2,58 \\
\hline $\operatorname{RAS}^{6}$ & 2,39 & 4,13 & 6,24 & 4,84 & 4,40 & 1,60 \\
\hline Coliformes totais $\left(\mathrm{NMP}^{7} 100 \mathrm{~mL}^{-1}\right)$ & $\mathrm{NR}^{8}$ & NR & NR & $2,42 \times 10^{3}$ & - & - \\
\hline Termotolerantes (NMP $100 \mathrm{~mL}^{-1}$ ) & NR & NR & NR & $1,51 \times 10^{2}$ & - & - \\
\hline
\end{tabular}


Os resultados apresentados na Tabela anterior estão relacionados ao processo de tratamento utilizado e à origem do efluente. Pulschen et al. (2013), ao realizarem o monitoramento desta ETE, concluíram que a eficiência na remoção de nitrogênio e fósforo é atribuída ao tanque de microalgas, uma vez que as microalgas clorofíceas, da espécie Desmodesmus subspicatus, que predominam no tanque, e durante o processo de fotossíntese, consomem parte destes nutrientes, proporcionando o aumento da eficiência da estação.

A condutividade elétrica em todas as análises permaneceu inferior a $0,75 \mathrm{dS} \mathrm{m}^{-1}$, valor proposto por Martinez e Silva Filho (2004) como parâmetro de qualidade da água para o preparo da solução nutritiva.

$\mathrm{O}$ valor do $\mathrm{pH}$ foi superior ao recomendado, pois segundo Castellane e Araújo (1995), a faixa de $\mathrm{pH}$ entre 6,0 a 6,5 é a melhor para o desenvolvimento vegetal, e valores acima dessa faixa podem produzir precipitações na solução, indisponibilizando elementos essenciais da solução, principalmente, cálcio, fósforo, ferro e manganês, acarretando crescimento reduzido da cultura. Para alcançar valores inferiores, Martinez (2006) recomenda adicionar à solução nutritiva, ácido nítrico, sulfúrico ou ortofosfórico, porém salienta a necessidade de considerar as quantidades de nutrientes por eles fornecidos.

Quanto aos teores de cálcio, magnésio, sódio e sulfatos, foram considerados normais quando comparados aos resultados das análises necessárias para se avaliar a qualidade da água de irrigação, de acordo com Ayers e Westcot (1999). Porém, o teor de potássio estabelecido pelos mesmos autores encontra-se acima dos valores normais, mas vale salientar que estes são padrões para aplicação no solo, e que para o uso como solução nutritiva este valor é considerado baixo. As variações nos teores de nutrientes entre as amostragens, principalmente de Nitrogênio Total Kjeldahl, é devido ao fato do esgoto ser doméstico originário da universidade e estar sujeito a sazonalidades (período de férias escolares).

A presença de Termotolerantes (Escherichia coli) no efluente visando o reuso em hidroponia é imprescindível, pois indica a contaminação e possibilita afirmar, com segurança, a possível presença de outros enteropatógenos (Sant'ana et al., 2003; WHO, 2002). Neste aspecto, a Companhia Ambiental do Estado de São Paulo (CETESB, 2001) determina as condições de reuso, permitindo somente aplicação em campos esportivos, parques públicos, cereais e ou cultura a ser industrializada, silvicultura, frutíferas, forragens para feno e silagem. Desta forma, independente da contagem de coliformes totais e termotolerantes (Escherichia coli) ainda não é permitido o uso deste tipo de efluente no cultivo de hortaliças.

\subsection{Solução nutritiva}

$\mathrm{O}$ monitoramento do $\mathrm{pH}$ e da condutividade elétrica dos três tratamentos realizado diariamente possibilitou verificar a ocorrência de oscilação dos valores do $\mathrm{pH}$ ao longo do cultivo. Porém, essa oscilação é esperada, considerando que a solução nutritiva não tem capacidade tampão (Backes et al., 2004). A média do pH no tratamento TA foi de 6,5; com desvio padrão de 0,3 , para o tratamento TRA foi de 6,6 , com desvio padrão de 0,3 e no tratamento TR, o pH médio foi de 8,3, com desvio padrão de 0,3 .

Os valores médios de $\mathrm{pH}$ dos tratamentos TA e TRA estão no limite superior da faixa considerada ideal para a absorção dos nutrientes, porém mesmo nestas condições, não foram observados sintomas visuais de deficiência de nutrientes. No tratamento TR o valor médio do pH ficou acima da faixa considerada ideal, sendo possível observar menor crescimento do sistema radicular das plantas deste tratamento quando comparado aos demais. Gomes et al. (2011) afirmam que o efeito direto sobre o crescimento de plantas cultivadas em solução nutritiva com $\mathrm{pH}$ acima do recomendado, é resultado da ação dos íons $\mathrm{OH}^{-}$sobre as membranas das células das raízes.

A condutividade elétrica média dos tratamentos TA e TRA foi ligeiramente superior à recomendada para o cultivo de alface em sistema hidropônico, de $2,73 \mathrm{dS} \mathrm{m}^{-1}$ com desvio 
padrão de 0,2 e de $2,52 \mathrm{dS} \mathrm{m}^{-1}$ com desvio padrão de 0,2 , respectivamente. Estes valores foram superiores a 2,5 dS m${ }^{-1}$, recomendado por Martinez e Silva Filho (2004), valor utilizado como referência para o preparo da solução nutritiva.

Apesar da condutividade elétrica e do $\mathrm{pH}$ terem alcançado valores superiores aos recomendados, nos tratamentos TA e TRA, isso não refletiu em redução da massa fresca. No tratamento TR a condutividade elétrica permaneceu estável, com pequenas variações, sendo a média de $0,4 \mathrm{dS} \mathrm{m}^{-1}$ e desvio padrão de 0,03 , reflexo da origem do efluente e do processo de tratamento empregado. No período em que o cultivo foi conduzido, no verão, é possível apontar que o maior consumo de água pelas plantas seja uma das causas do aumento da condutividade elétrica nos tratamentos TA e TRA, relacionando-o aos fatores climáticos e a evapotranspiração. Outro fator que também corroborou, foi o manejo da solução nutritiva, onde a reposição dos sais foi feita em relação ao volume de solução nutritiva nos reservatórios.

A quantidade de fertilizantes minerais utilizada nos tratamentos TA e TRA estão descritas na Tabela 2. Com o uso do efluente como fonte de água e de nutrientes para o preparo da solução nutritiva, foi possível uma redução na quantidade de alguns fertilizantes aplicados no tratamento TRA, comparado ao tratamento TA, sem prejuízos para a cultura.

Tabela 2. Comparação da quantidade de fertilizantes minerais adicionados no tratamento com água de abastecimento (TA) e no tratamento com esgoto doméstico tratado e complementado com fertilizantes minerais (TRA).

\begin{tabular}{lccc}
\hline \multirow{2}{*}{ Fertilizantes } & \multicolumn{2}{c}{ Total Aplicado } & \multirow{2}{*}{$\begin{array}{c}\text { Porcentagem de } \\
\text { economia }(\%)\end{array}$} \\
\cline { 2 - 3 } & TA $(\mathrm{g})$ & TRA $(\mathrm{g})$ & 11 \\
\hline Nitrato de cálcio & 990,0 & 882,9 & 44 \\
Sulfato de magnésio & 544,5 & 302,3 & 49 \\
Cloreto de potássio & 151,8 & 76,6 & 11 \\
Fosfato monoamônico & 156,2 & 139,7 & \\
\hline
\end{tabular}

\subsection{Avaliação agronômica}

Os resultados da análise foliar (Tabela 3) de amostras de alface dos diferentes tratamentos foram comparados com a faixa de teores adequados de macronutrientes e micronutrientes estabelecida por Raij et al. (1997).

Tabela 3. Resultados da análise química foliar das amostras das plantas de alface dos diferentes tratamentos.

\begin{tabular}{lcccccc}
\hline \multirow{2}{*}{ Tratamentos } & \multicolumn{5}{c}{ Macronutrientes $\left(\mathrm{g} \mathrm{kg}^{-1}\right)$} \\
& $\mathrm{N}$ & $\mathrm{P}$ & $\mathrm{K}$ & $\mathrm{Ca}$ & $\mathrm{Mg}$ & $\mathrm{S}$ \\
\hline TA & 41,25 & 5,91 & 38,45 & 2,58 & 1,13 & 1,69 \\
TRA & 47,25 & 5,66 & 36,4 & 2,63 & 1,18 & 1,63 \\
TR & 23,13 & 2,4 & 14,58 & 1,81 & 0,88 & 0,87 \\
\cline { 2 - 7 } & \multicolumn{5}{c}{ Micronutrientes $\left(\mathrm{g} \mathrm{kg}^{-1}\right)$} \\
TA & $\mathrm{B}$ & $\mathrm{Cu}$ & $\mathrm{Fe}$ & $\mathrm{Mn}$ & $\mathrm{Zn}$ \\
TRA & & 0,03 & 0,006 & 0,1 & 0,09 & 0,01 \\
TR & 0,03 & 0,004 & 0,1 & 0,05 & 0,01 \\
& & 0,007 & 0,002 & 0,03 & 0,03 & 0,007 \\
\hline
\end{tabular}


Para os tratamentos TA e TRA os teores de potássio, cálcio, magnésio, cobre e zinco encontraram-se abaixo da faixa recomendada para a cultura do alface, de acordo com Raij et al. (1997), mas as plantas não apresentaram sintoma de deficiência destes nutrientes. A ocorrência destas deficiências identificada somente por meio da análise foliar pode estar relacionada ao valor do $\mathrm{pH}$ das soluções nutritivas destes tratamentos, uma vez que o $\mathrm{pH}$ mais elevado pode causar a precipitação de alguns nutrientes. Para os demais macronutrientes e micronutrientes os valores permaneceram na faixa adequada.

No tratamento TR, os sintomas de deficiência nutricional foram verificados visualmente, consequência da baixa quantidade de nutrientes do esgoto tratado usado como solução nutritiva, e também do $\mathrm{pH}$ inadequado, e o resultado da análise do tecido foliar também apontou deficiência de todos os nutrientes, comparado ao recomendado por Raij et al. (1997). Neste tratamento, as plantas aos cinco dias após o transplante, já apresentavam os primeiros sinais de deficiência de nitrogênio, com amarelecimento das folhas. A partir da metade do ciclo da cultura, notou-se deficiência de cálcio, com o aparecimento de necrose dos meristemas foliares, conhecido como "tip burn", necrose dos ápices radiculares, e um aspecto de roseta na gema apical. No final do ciclo surgiram pequenas pontuações de coloração marrom, observadas nas bordas das folhas mais velhas, sintoma condizente com de deficiência de potássio.

A análise de variância da massa fresca das amostras de plantas de alface coletadas, nos diferentes tratamentos não indicou diferença significativa entre os blocos, porém entre os tratamentos a diferença foi altamente significativa (Tabela 4).

Tabela 4. Análise de variância da massa fresca das amostras de plantas de alface de cada tratamento (g planta ${ }^{-1}$ ) do cultivo de verão.

\begin{tabular}{|c|c|c|c|c|}
\hline Causas de Variação & GL & SQ & QM & $\mathbf{F}$ \\
\hline Blocos & 3 & 189,52 & 63,17 & $0,3377 \mathbf{~ n s}$ \\
\hline Tratamentos & 2 & 115653,73 & 57826,86 & $309,1024^{* *}$ \\
\hline Resíduo & 6 & 1122,48 & 187,08 & \\
\hline Total & 11 & 116965,74 & & \\
\hline
\end{tabular}

O teste de Tukey a $5 \%$ de probabilidade foi aplicado às médias da massa fresca das plantas de alface da área útil de cada parcela (Tabela 5) e os resultados não indicaram diferença significativa entre as médias dos tratamentos TA e TRA, porém a diferença destes com o tratamento TR foi significativa $(\mathrm{p}<0,01)$. Este resultado confirma o efeito negativo da deficiência de nutrientes e do $\mathrm{pH}$ alcalino verificado no tratamento TR sobre o crescimento das plantas.

Tabela 5. Valores médios da massa fresca de plantas de alface $\left(\mathrm{g} \operatorname{planta}^{-1}\right)$ dos tratamentos do cultivo de verão.

\begin{tabular}{lcccccc}
\hline Massa fresca & TA & TRA & TR & CV \% & dms & P \\
\hline Média $\left(\right.$ g planta $\left.^{-1}\right)$ & $330,68 \mathrm{a}$ & $322,73 \mathrm{a}$ & $118,57 \mathrm{~b}$ & 5,32 & 29,68 & $<0,01$ \\
\hline
\end{tabular}

Nota: As médias seguidas pela mesma letra não diferem estatisticamente entre si. Foi aplicado o teste de Tukey ao nível de 5\% de probabilidade. CV\%: coeficiente de variação entre os resultados de cada tratamento; dms: diferença mínima significativa. 


\subsection{Análise microbiológica}

A análise microbiológica indica as condições de higiene durante o cultivo e a manipulação das plantas de alface. No Brasil, pelo fato da prática do reuso de efluentes para o cultivo de hortaliças em sistema hidropônico não ser permitida, não existem limites para estes parâmetros microbiológicos. Portanto, para efeito de comparação, foi usado como referência a Resolução RDC no 12 de 02 de Janeiro de 2001, que estipula como padrões microbiológicos para hortaliças frescas, in natura, preparadas, sanificadas, refrigeradas ou congeladas, para o consumo direto, limite máximo de $10^{2}$ coliformes termotolerantes (ANVISA, 2001).

Os resultados obtidos em todos os tratamentos (Tabela 6) atendem ao padrão estabelecido pela RDC $\mathrm{n}^{\mathrm{o}} 12$ de 02/01/2001 (ANVISA, 2001), que foram ausentes para a termotolerantes (Escherichia coli). Apesar de todas as amostras apresentarem coliformes totais, a contagem foi baixa. Resultado semelhante foi encontrado por Perin (2006) ao cultivar alface em sistema hidropônico com efluente oriundo de uma lagoa de polimento, porém Rababah (2007) ao utilizar este sistema de cultivo como tratamento primário para esgoto bruto municipal obteve plantas contaminadas e impróprias para o consumo.

Apesar da presença da bactéria Escherichia coli no efluente usado nos tratamentos TRA e TR, esta não foi encontrada nas análises microbiológicas realizadas nas plantas de alface. Isso provavelmente se deve ao fato de não ter ocorrido o contato direto das folhas com o efluente durante o cultivo, assim como, aos cuidados durante a coleta das raízes, de forma a não permitir o contato com a parte aérea das plantas de alface.

Tabela 6. Análise microbiológica das plantas de alface cultivadas com efluente de esgoto doméstico tratado na ETE do CCA da UFSCar, em Araras (SP).

\begin{tabular}{lcc}
\hline Tratamento & $\begin{array}{c}\text { Coliformes totais } \\
\left(\mathrm{UFC}^{\mathbf{1}} \mathrm{mL}^{-1}\right)\end{array}$ & $\begin{array}{c}\text { Escherichia coli } \\
\left(\mathrm{UFC} \mathrm{mL}^{-1}\right)\end{array}$ \\
\hline TA & 12,50 & $\mathrm{AU}^{2}$ \\
TRA & 87,50 & $\mathrm{AU}$ \\
TR & 93,75 & $\mathrm{AU}$ \\
\hline
\end{tabular}

1UFC: Unidades formadoras de colônias; ${ }^{2}$ AU: Ausente.

\section{CONCLUSÃO}

Nas condições experimentais foi possível concluir que a aplicação do efluente gerado na ETE do CCA da UFSCar, em Araras (SP) como fonte alternativa de água para o cultivo hidropônico de alface, mostrou-se satisfatória, com uma economia de alguns fertilizantes em relação à solução nutritiva recomendada, não havendo prejuízos da produtividade da cultura, desde que este efluente seja complementado com fertilizantes minerais para atender a demanda nutricional da cultura.

A análise microbiológica das plantas indicou que os perfis hidropônicos podem impedir o contato da parte comestível das plantas com o efluente usado na solução nutritiva.

\section{AGRADECIMENTOS}

Ao CCA/UFSCar, ao Programa de Pós-Graduação em Agricultura e Ambiente, a FAPESP, CNPQ e CAPES, ao grupo de estudos e pesquisas EASA, o grupo de estudos GEHORT pelo apoio estrutural, a empresa Lumaplastic pela colaboração com alguns materiais e a IBS Mudas pela doação das mudas e ao PPGAA. 


\section{REFERÊNCIAS}

AGÊNCIA NACIONAL DE VIGILÂNCIA SANITÁRIA - ANVISA (Brasil). Resolução - RDC no. 12, de 02 de janeiro de 2001. Disponível em:< http://portal.anvisa.gov.br/wps/wcm/connect/a47bab8047458b909541d53fbc4c67 35/RDC_12_2001.pdf?MOD=AJPERES >. Acesso em: 10 fevereiro 2013.

AMERICAN PUBLIC HEALTH ASSOCIATION - APHA. Standards Methods for the Examination of Water and Wastewater. 22. ed. Washington, DC, 2012.

AL-ZBOON, K.; AL-ANANZEH, N. Performance of wastewater treatment plant in Jordan and suitability for reuse. African Journal of Biotechnology, v. 7, n. 15, p. 2621-2629, 2008.

AZEVEDO, M.; KONIG, A.; BELTRÃO, N.; AZEVEDO, C.; TAVARES, T.; SOARES, F. Efeito da irrigação com água residuária tratada sobre a produção de milho forrageiro. Revista Brasileira de Ciências Agrárias (Agrária, v. 2, p. 63 68, 2007.

AYERS, R. S.; WESTCOT, D. W. A qualidade de água na agricultura. 2. ed. Campina Grande: UFPB, 1999. 153 p. (FAO - Estudos Irrigação e Drenagem, 29).

BACKES, F. A. A. L.; SANTOS, O. S. S.; PILAU, F. G.; BONNECARRÈRE, R. A. G.; MEDEIROS, S. L. P.; FAGAN, E. B. Reposição de nutrientes em solução nutritiva para o cultivo hidropônico de alface. Ciência Rural, v. 34, n. 5, p. 1407 1414, 2004. http://dx.doi.org/10.1590/S0103-84782004000500013

BLUM, J. R. C. Critérios e padrões de qualidade da água. In: MANCUSO, P. C. S.; SANTOS, H. F.; PHILIPPI JR, A. (Coord.). Reuso de Água. Barueri: Manole, 2003. p. 125-174.

BONINI, M. A.; SATO, L. M.; BASTOS, R. G.; SOUZA, C. F. Alterações nos atributos químico e físicos de um Latossolo Vermelho irrigado com água residuária e vinhaça. Revista Biociências, Taubaté, v. 20, p. 56-63, 2014.

BOYDEN, B. H.; RABABAH, A. A. Recycling nutrients from municipal wastewater. Desalination, v. 106, n. 1-3, p. 241-246, 1996. http://dx.doi.org/10.1016/S00119164(96)00114-2

CASTEllane, P. D.; ARAÚJO. J. A. C. Cultivo sem solo: hidroponia. Jaboticabal: Faculdade de Ciências Agronômica e Veterinária; FUNEP, 1995. 43p.

COMPANHIA AMBIENTAL DO ESTADO DE SÃO PAULO - CETESB. Orientação para apresentação de projeto visando a aplicação de água de reuso proveniente de estação de tratamento de esgoto doméstico na agricultura. Aplicação de água de reuso de ETE na agricultura. São Paulo, 2001. 11 p. Disponível em: <http://www.cetesb.sp.gov.br/areas-contaminadas/manual-degerenciamento-de-areas-contaminadas/7-manual-de-gerenciamento-das--acs > Acesso em: maio 2014.

COMPANHIA AMBIENTAL DO ESTADO DE SÃO PAULO - CETESB. Guia nacional de coleta e preservação de amostras: água, sedimento, comunidades aquáticas e efluentes líquidos. São Paulo, 2011. 326 p. 
CONSELHO NACIONAL DE RECURSOS HÍDRICOS CNRH (Brasil). Resolução no 54, de 28 de Novembro de 2005. Estabelece modalidades, diretrizes e critérios gerais para a prática de reuso direto não potável de água, e dá outras providências. Presidente: Marina Silva. Diário Oficial [da] União, Brasília, 09 mar. 2006.

FOOD AND AGRICULTURE ORGANIZATION - FAO. Wastewater treatment and use in agriculture. Roma, 1992. 125p. (Irrigation and Drainage Paper, n.47)

FLORENCIO, L.; BASTOS, R. K. X.; AISSE, M. M. Tratamento e utilização de esgotos sanitários. Rio de Janeiro: ABES, 2006. 426p.

FURLANI, P. R. Hydroponic vegetable production in Brazil. Acta Horticulturae, v. 2, n. 481, p. 777-778, 1999.

GOMES, L.; MARTINS, C.; NOGUEIRA, N.; LOPES, F.; XAVIER, T.; CARDOSO, L. Efeito de diferentes valores de $\mathrm{pH}$ da solução nutritiva no desenvolvimento de variedades de melão. Revista Brasileira de Ciências Agrárias (Agrária), v. 6, p. 73- 78, 2011. http://dx.doi.org/10.5039/agraria.v6i1a922

HESPANHOL, I. Potencial de reuso de água no Brasil - agricultura, indústria, municípios e recarga de aquíferos. Revista Brasileira de Recursos Hídricos, v. 7, p. 75-95, 2002.

KELLER, R.; PERIN, K.; SEMIONATO, S.; ZANDONADE, E.; CASSINI, S.; GONÇALVES R. F. Hydroponic cultivation of lettuce (Lactuca sativa) using effluents from primary, secondary and tertiary + UV treatments. Water Science and Technology: Water Supply, v. 5, n. 1, p. 95- 100, 2005.

MARTINEZ, H. E. P. Manual prático de hidroponia. Viçosa: UFV. 2006. 271p.

MARTINEZ, H. E. P.; SILVA FILHO, J. B. Introdução ao cultivo hidropônico de plantas. 2. ed. Viçosa: UFV, 2004. 111 p.

MARTÍNEZ, S.; SUAY, R.; MORENO, J.; SEGURA, M. L. Reuse of tertiary municipal wastewater effluent for irrigation of Cucumis melo L. Irrigation Science, v.31, p.661-672, 2013. http://dx.doi.org/10.1007/s00271-012-0342-4

MELO, H. N. S.; MELO FILHO, C.; PEREIRA, M. G.; OLIVEIRA, F. K. D.; ANDRADE NETO, C. O. Uso de esgoto doméstico tratado em filtros anaeróbios como fonte de macro e micronutrientes para cultivos hidropônicos. Vitória: PROSAB, 2002.

OTTOSON, J.; NORSTRO, A.; DALHAMMAR, G. Removal of micro-organisms in a small-scale hydroponics wastewater treatment system. The Society for Applied Microbiology, Letters in Applied Microbiology, v. 40, p. 443-447, 2005. http://dx.doi.org/10.1111/j.1472-765X.2005.01689.x

PERIN, K. Reuso de efluente de lagoa de polimento no cultivo de alface hidropônica (Lactuca sativa L.) e de plantas de feijão (Phaseolus vulgaris L.). 2006. 165f. Dissertação (Mestrado em Engenharia Ambiental) - Universidade Federal do Espírito Santo, Centro Tecnológico. Vitória, 2006. 
PUlShEN, A.; GOMES, M. P. M.; BASTOS, R. G.; SOUZA, C. F. Tratamento biológico de efluentes sanitários em ETE mista. In: SIMPÓSIO INTERNACIONAL SOBRE GERENCIAMENTO DE RESÍDUOS AGROPECUÁrios E AGROINDUSTRIAIS, 3., 2013, São Pedro. Anais do... São Pedro: SIGERA, 2013.

RABABAH, A. Hydroponics removal of wastewater's contaminants for the generation of commercially valuable plants and environmentally sound effluent for the dead sea communities. Jordan Journal of Civil Engineering, v. 1, n. 3, p. 273- 286, 2007.

RABABAH, A.; ASHBOLT N. J. Innovative production treatment hydroponic farm for primary municipal sewage utilisation. Water Research, Sydney, v. 34, n. 3, p. 825-834, 2000. http://dx.doi.org/10.1016/S0043-1354(99)00231-6

RAIJ, B. van; CANTAREllA, J. A.; QUAGGIO, J. A.; FURLANI, A. M. C. Recomendações de adubação e calagem para o Estado de São Paulo. Campinas: Instituto Agronômico, 1997. 285 p. (Boletim Técnico, n. 100).

SALA, F. C.; COSTA, C. P. Retrospectiva e tendência da alfacicultura brasileira. Horticultura Brasileira, v. 30, n. 2, p. 187-194, 2012.

http://dx.doi.org/10.1590/S0102-05362012000200002

SANT'ANNA, A. S.; SILVA, S. C. F.; FARANI, I. O.; AMARAL, C. H. R.; MACEDO, V. F. Qualidade microbiológica de águas minerais. Ciência e Tecnologia de Alimentos, v. 23, p. 190-194, 2003. Supl.

SETZER, J. Atlas climático e ecológico do Estado de São Paulo. São Paulo: Comissão interestadual da Bacia Paraná-Uruguai, 1967.

SHAER-BARBOSA, M.; SANTOS, M. E. P.; MEDEIROS, Y. D. P. Viabilidade do réuso de água como elemento mitigador dos efeitos da seca no semiárido da Bahia. Ambiente e Sociedade, v. 17, n. 2, p. 17-32, 2014. http://dx.doi.org/10.1590/S1414-753X2014000200003

SOUSA, J. T.; CEBALLOS, B. S. O.; HENRIQUE, I. N.; DANTAS, J. P.; LIMA, S. M. S. Reuso de água residuárias na produção de pimentão (Capsicum annum L.). Revista Brasileira de Engenharia Agrícola e Ambiental, v. 10, n. 1, p. 89 -96, 2006. http://dx.doi.org/10.1590/S1415-43662006000100014

WORLD HEALTH ORGANIZATION - WHO. Global strategy for food safety: safer food for better health. 2002. Disponível em: <http://whqlibdoc.who .int/publications/9241545747.pdf>. Acesso em: $10 \mathrm{dez} .2013$.

WORD HEALTH ORGAZINATION - WHO. Water Security \& the Global Water. Agenda AUN-Water Analytical Brief. Canada, 2013. (Report of a WHO meeting of experts). Disponível em: <http://whqlibdoc.who.int/publications/9241545747.pdf>. Acesso em: 19 jun. 2013. 